\title{
Investigation on the reactivity of $\alpha$-azidochalcones with carboxylic acids: Formation of $\alpha$-amido-1,3-diketones and highly substituted 2-(trifluoromethyl)oxazoles
}

\author{
Kandasamy Rajaguru ${ }^{1}$, Arumugam Mariappan ${ }^{1}$, Rajendran Suresh ${ }^{2}$, \\ Periasamy Manivannan ${ }^{1}$ and Shanmugam Muthusubramanian ${ }^{* 1}$
}

\author{
Full Research Paper \\ Address: \\ ${ }^{1}$ Department of Organic Chemistry, School of Chemistry, Madurai \\ Kamaraj University, Madurai, 625 021, India and ${ }^{2}$ Syngene \\ International Limited, Biocon, Bangalore, 560 100, India \\ Email: \\ Shanmugam Muthusubramanian* - muthumanian2001@yahoo.com \\ * Corresponding author \\ Keywords: \\ a-amido-1,3-diketones; $\alpha$-azidochalcones; carboxylic acids; \\ $2 \mathrm{H}$-azirines; oxazoles
}

\author{
Beilstein J. Org. Chem. 2015, 11, 2021-2028. \\ doi:10.3762/bjoc.11.219 \\ Received: 23 June 2015 \\ Accepted: 06 October 2015 \\ Published: 29 October 2015 \\ Associate Editor: B. Stoltz \\ (C) 2015 Rajaguru et al; licensee Beilstein-Institut. \\ License and terms: see end of document.
}

\begin{abstract}
The reaction of $\alpha$-azidochalcones with carboxylic acids has been investigated resulting in the formation of $\alpha$-amido-1,3-diketones under microwave irradiation via in situ formation of $2 \mathrm{H}$-azirine intermediates. An interesting reaction is described wherein, with trifluoroacetic acid at lower temperature, it affords highly substituted 2-(trifluoromethyl)oxazoles. These flexible transformations proceed under solvent free conditions in good to excellent yields without any catalyst.
\end{abstract}

\section{Introduction}

$\alpha$-Azidochalcones are one of the most attractive three-atom synthons for the formation of nitrogen-containing organic motifs. Due to their versatile reactivity, they have attracted considerable attention since last decade [1-6]. In drug discovery, secondary amides are an important class of compounds. The $N$-(2-keto)amide skeleton is of particular interest, as it serves as a synthetic precursor for various small heterocyclic compounds such as imidazoles, oxazoles and thiazoles [7-9]. Azirine, the smallest nitrogen-containing unsaturated three-membered heterocyclic system, is well known as a reactive intermediate in several synthetic transformations [10-15].
The chemistry of $2 \mathrm{H}$-azirines has been extensively explored because of its strained molecular structure, unique reactivity and synthetic applications [10-22]. $\alpha$-Substituted $2 H$-azirines are impressive intermediates for the synthesis of various substituted heterocyclic compounds [23-25]. Nucleophiles can interact with the electrophilic carbon of the strained $2 \mathrm{H}$-azirine rings and due to the ring strain in the three-membered $2 H$-azirine ring system A1, the electrophilic character of the $\mathrm{C}(2)-\mathrm{N}$ double bond is higher than a normal imine (Figure 1) $[10,26,27]$. The generated substituted aziridines A2 may undergo further ring opening reactions. The $\alpha$-azidochalcones 1 
are suitable as precursors for the generation of $2 H$-azirines $\mathbf{A 1}$, though several other methods are available (Figure 2) [10,24].

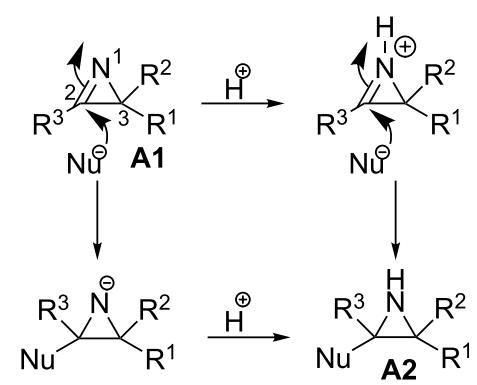

Figure 1: Formation of substituted aziridine.

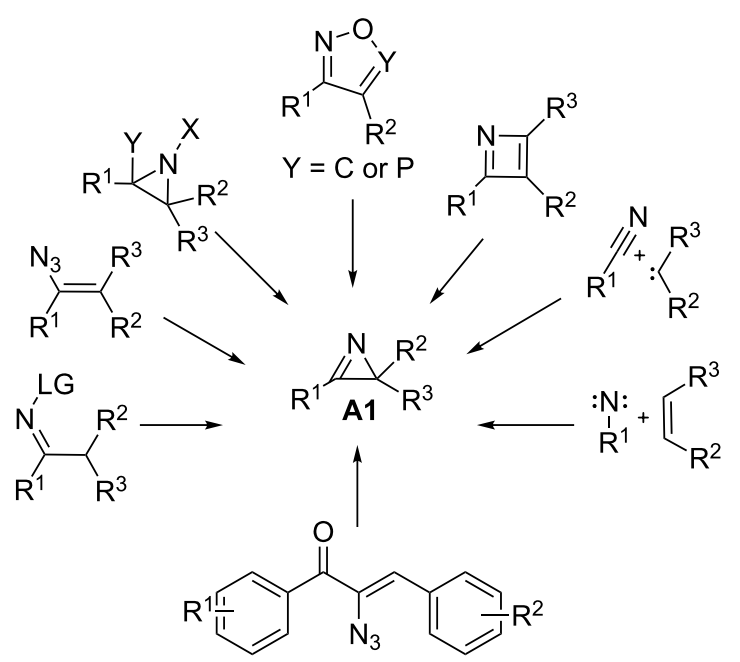

Figure 2: Various strategies for the formation of $2 \mathrm{H}$-azirine.

In this article, we intend to demonstrate the reactivity of $2 \mathrm{H}$-azirine $\mathbf{A} \mathbf{1}$ towards carboxylic acids [28]. $\alpha$-Azidochalcones have been chosen to generate $2 H$-azirines via vinyl nitrene intermediates. $\alpha$-Azidochalcones can be synthesized from the corresponding benzylidene acetophenones in two steps following a literature procedure [29].

\section{Results and Discussion}

The investigation was initiated by treating $\alpha$-azidochalcone 1a $\left(\mathrm{R}^{1}=4-\mathrm{Br}, \mathrm{R}^{2}=4-\mathrm{OMe}\right)$ with trifluoroacetic acid (2a). This acid was allowed to react with the azidochalcone at room temperature for 30 minutes and a low yield of 3a (34\%) was noticed with undesirable side products. Due to operational simplicity and efficiency, microwave irradiation in organic synthesis has become more popular as an environmental friendly way [30-32]. Thus, to increase the product yield, the investigation was continued by treatment of $\alpha$-azidochalcone $\mathbf{1 a}$ $\left(\mathrm{R}^{1}=4-\mathrm{Br}, \mathrm{R}^{2}=4-\mathrm{OMe}\right)$ with trifluoroacetic acid under microwave conditions [33] at $100{ }^{\circ} \mathrm{C}$ for 2 minutes to obtain diketone 3a $(79 \%)$ as a solid without any side products (Scheme 1).

The ${ }^{1} \mathrm{H}$ NMR spectrum of $\mathbf{3 a}$ exhibits a methine proton doublet at $6.78 \mathrm{ppm}$. In the ${ }^{13} \mathrm{C} \mathrm{NMR}$ spectrum, two carbonyl carbon signals and an amide carbon signal appear at 190.6, 188.8, and $165.1 \mathrm{ppm}$, respectively. In addition, a methine carbon signal appears at $60.4 \mathrm{ppm}$. The structural confirmation of $\alpha$-amido1,3-diketone 3e by one- and two-dimensional NMR spectroscopic data is depicted (see Supporting Information File 1).

With this optimised protocol, we subsequently extended the scope of this transformation with other carboxylic acids as well. The reaction works well with different acids including acetic acid (2b) (3c--h) and chloroacetic acid (2c) (3i and $\mathbf{3 j}$ ). It should be mentioned that the reaction goes well with various substituted benzoic acids $\mathbf{2 d -} \mathbf{g}$ as well and the resultant $\alpha$-amido-1,3diketones $\mathbf{3 k}-\mathbf{o}$ are obtained in moderate to good yields (Figure 3).

The mechanism for the formation of $\alpha$-amido-1,3-diketone 3 is given in Scheme 2. Initially, by thermolysis, $\alpha$-azidochalcone undergoes denitrogenative decomposition to form a cyclic imine - a highly strained three-membered $2 H$-azirine, 4 . Subsequent attack by the acid results in the aziridine adduct $\mathbf{5}$, which then undergoes intramolecular nucleophilic addition on the carboxylic group with the nitrogen lone pair, ultimately yielding $\alpha$-amido-1,3-diketone 3 by ring opening of 6 (Scheme 2).<smiles>COc1ccc(C(=O)C(NC(=O)C(F)(F)F)C(=O)c2ccc(Br)cc2)cc1</smiles> 


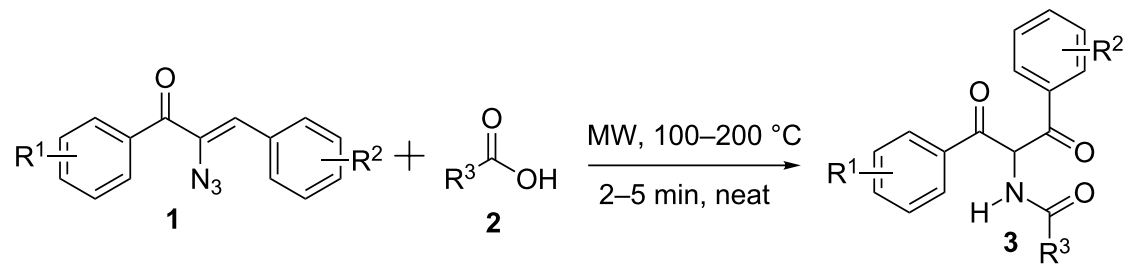<smiles>COc1ccc(C(=O)C(NC(=O)C(F)(F)F)C(=O)c2ccc(Br)cc2)cc1</smiles>

3a; $79 \%$<smiles>COc1ccc(C(=O)C(NC(C)=O)C(=O)c2ccc(Cl)cc2)cc1</smiles>

3e; $90 \%$<smiles>Cc1ccc(C(=O)C(NC(=O)CCl)C(=O)c2ccc(Cl)cc2)cc1</smiles>

$3 \mathbf{i} ; 88 \%$<smiles>Cc1ccc(C(=O)C(NC(=O)C(F)(F)F)C(=O)c2ccc(Cl)cc2)cc1</smiles>

3b; $79 \%$<smiles>CC(=O)NC(C(=O)c1ccccc1)C(=O)c1ccccc1</smiles>

3f; $72 \%$<smiles>COc1ccc(C(=O)C(NC(C)=O)C(=O)c2ccc(Br)cc2)cc1</smiles>

3c; $82 \%$<smiles>CC(=O)NC(C(=O)c1ccc(C)cc1)C(=O)c1ccc(Cl)cc1</smiles>

3d; $85 \%$<smiles>CC(=O)NC(C(=O)c1ccc(Cl)cc1)C(=O)c1cccs1</smiles>

3h; $88 \%$

3g; $79 \%$<smiles>Cc1ccc(C(=O)C(NC(=O)c2ccc([N+](=O)[O-])cc2)C(=O)c2ccc(Cl)cc2)cc1</smiles><smiles>Cc1ccc(C(=O)C(NC(=O)c2ccccc2)C(=O)c2ccc(Cl)cc2)cc1</smiles><smiles>Cc1ccc(C(=O)C(NC(=O)c2ccccc2Cl)C(=O)c2ccc(Cl)cc2)cc1</smiles><smiles>Cc1ccc(C(=O)C(NC(=O)c2cc(F)c(Cl)cc2F)C(=O)c2ccc(Cl)cc2)cc1</smiles>

Figure 3: Synthesis of $\alpha$-amido-1,3-diketone (3a-o). Reaction conditions: $\alpha$-azidochalcone 1 (1.0 equiv) and carboxylic acid 2 (1.0 equiv), 100-200 ${ }^{\circ} \mathrm{C}, 2-5 \mathrm{~min}$. 


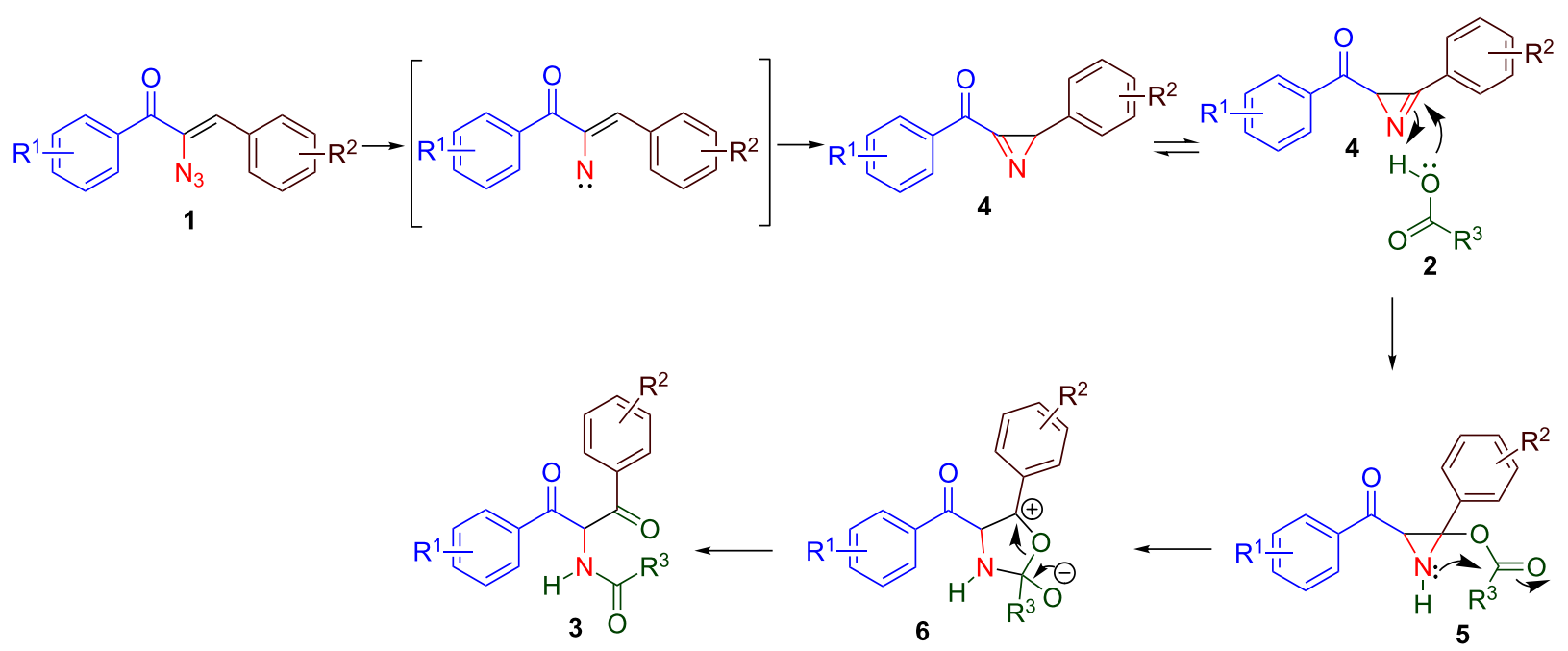

Scheme 2: Plausible mechanism.

Having established the formation of $\mathbf{3}$ from azidochalcones with carboxylic acids under microwave conditions, the efficiency of this conversion was checked by replacing the carboxylic acids with equivalent systems such as acid chlorides, thioacetic acids, anhydrides, esters and amides under the same conditions. However, the expected products were not formed, emphasising the need for the hydroxy group in product formation (Scheme 3).

Compounds 3 have 1,4-dicarbonyl functionality and are capable undergoing further useful transformations yielding different heterocyclic systems. This is illustrated with one reaction in which 3 was subjected to treatment with triphenylphosphine in the presence of iodine and triethylamine in dry dichloromethane at room temperature (Scheme 4) [34,35]. As expected, compounds 3 are converted to 2,4,5-substituted oxazole 7 regiospecifically in good to excellent yield.

Compounds $7 \mathbf{a}$ and $\mathbf{7 b}$ have been characterized by one and twodimensional NMR spectroscopy (see Supporting Information File 1). It can be noticed that the cyclisation could have

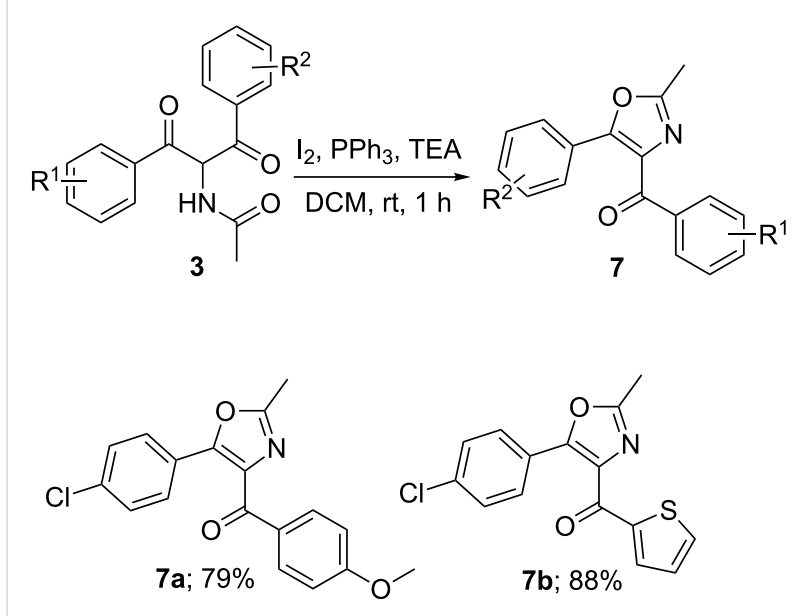

Scheme 4: Oxazole formation from 3.

happened in two different ways yielding either 7 or $\mathbf{7}^{\prime}$ (Figure 4). The fact that the compound formed is $\mathbf{7}$ and not $\mathbf{7}$ is confirmed by the HMBC spectrum of 7a. The carbonyl carbon at $187.1 \mathrm{ppm}$ has a HMBC contour with the hydrogens<smiles>[R]#CC=CC=C(N)C(=O)c1cc[R1]cc1</smiles>

1

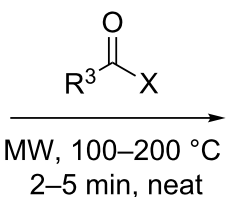<smiles>[R]CC(=O)c1ccccc1C(=O)C(C(=O)c1cc[R1]cc1)N(C)C([R])=O</smiles>

$0 \%$ yield 
<smiles>[3H][Te]C(=[18O])c1nc(C)oc1[Al]</smiles><smiles>Cc1nc(C(=O)[Al])c([Al])o1</smiles>

Figure 4: Possible isomers for 7.

at $8.11 \mathrm{ppm}$, which have been shown to be meta to methoxy not meta to chloro by an H,H-COSY experiment.

When the $\alpha$-azidochalcone $\mathbf{1}\left(\mathrm{R}^{1}=\mathrm{H}, \mathrm{R}^{2}=\mathrm{H}\right)$ was treated with trifluoroacetic acid at $0{ }^{\circ} \mathrm{C}$ and allowed to warm to ambient temperature for $30 \mathrm{~min}, \mathbf{8 a}$ was obtained (Scheme 5) [36].

In ${ }^{1} \mathrm{H}$ NMR spectrum of $\mathbf{8 a}$, there is no methine proton signal as in the case of $\mathbf{3}$ and in the ${ }^{13} \mathrm{C}$ NMR spectrum, only one carbonyl carbon signal was observed at $187.3 \mathrm{ppm}$ with no amide car- bonyl carbon. The investigation of the structure of $\mathbf{8 a}$ indicated that the compound is a highly substituted 2-(trifluoromethyl)oxazole. With different $\alpha$-azidochalcones, differently substituted 8 have been isolated (Figure 5).

It should be mentioned that oxazole formation is observed only at low temperature with trifluoroacetic acid and not with other carboxylic acids. A plausible mechanism has been illustrated for the formation of substituted oxazoles (Scheme 6). Initial attack of trifluoroacetic acid on the azide via Michael addition affords active intermediate 9. Subsequently, an intramolecular nucleophilic addition takes place to form intermediate 10. This is followed by the elimination of water leading to $\mathbf{8}$. The reaction goes on the azide directly at low temperature, while at elevated temperature, it proceeds through azirine intermediates.

\section{Conclusion}

In conclusion, the present work describes a new strategy for the synthesis of $\alpha$-amido-1,3-diketones and highly substituted<smiles>CCOCC(C)C(=O)O</smiles>

1<smiles>O=C(c1ccccc1)c1nc(C(F)(F)F)oc1-c1ccccc1</smiles>

Scheme 5: Oxazole formation.<smiles>[R][R]1ccc(-c2oc(C(F)(F)F)nc2C(=O)c2ccccc2-c2oc(C)nc2C)cc1</smiles><smiles>O=C(c1ccccc1)c1nc(C(F)(F)F)oc1-c1ccccc1</smiles><smiles>O=C(c1ccccc1Br)c1nc(C(F)(F)F)oc1-c1ccc(Br)cc1</smiles><smiles>COc1cccc(-c2oc(C(F)(F)F)nc2C(=O)c2ccc([N+](=O)[O-])cc2)c1</smiles><smiles>COc1ccc(C(=O)c2nc(C(F)(F)F)oc2-c2ccc(OC)c(OC)c2Cl)cc1</smiles><smiles>Cc1ccc(-c2oc(C(F)(F)F)nc2C(=O)c2ccc(Cl)cc2Cl)cc1</smiles> 


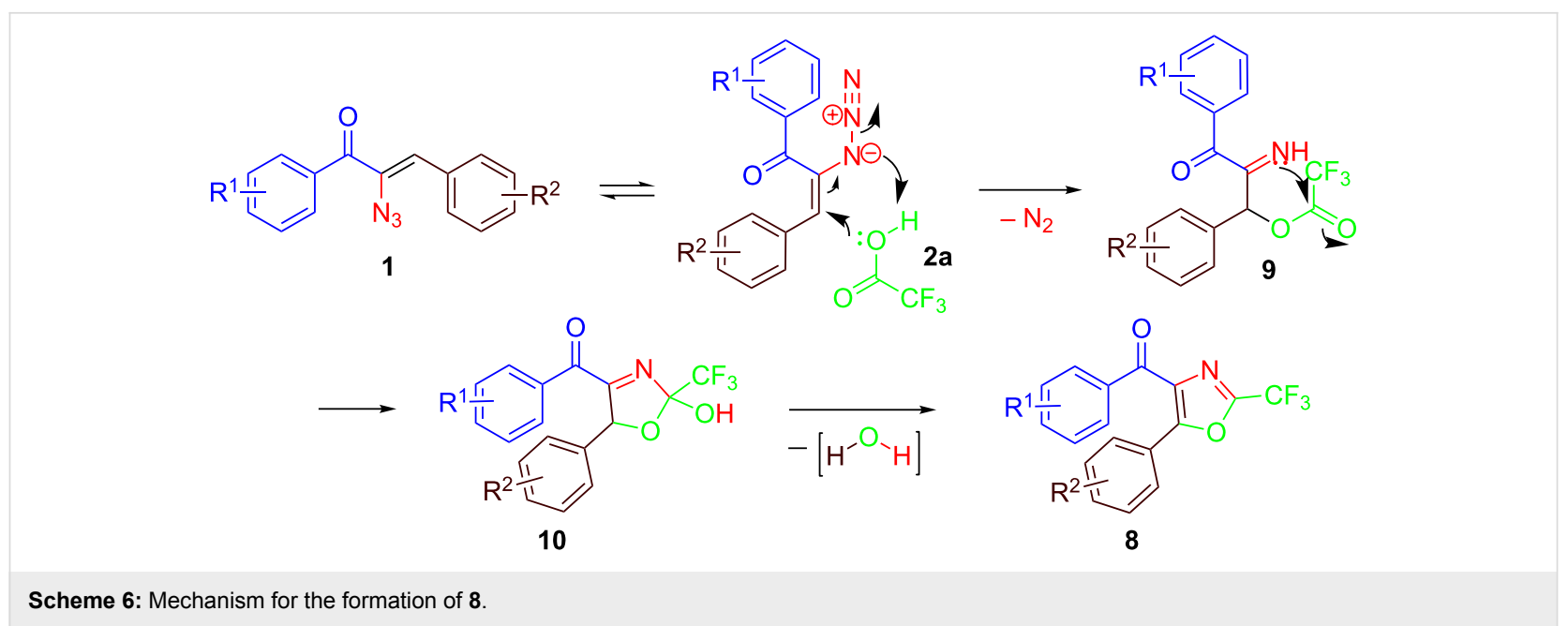

2-(trifluoromethyl)oxazoles from $\alpha$-azidochalcones and commercially available carboxylic acids without any catalyst in high yields. The entire sequence is realized under mild and simple conditions. This reaction is synthetically useful for the construction of other heterocyclic systems.

\section{Experimental}

\section{General}

A CEM Discover microwave synthesizer (Model No: 908010) operating at $180 / 264 \mathrm{~V}$ and $50 / 60 \mathrm{~Hz}$ with microwave power maximum level of $300 \mathrm{~W}$ and microwave frequency of $2455 \mathrm{MHz}$ was employed for the microwave-assisted experiments. Nuclear Magnetic Resonance $\left({ }^{1} \mathrm{H},{ }^{13} \mathrm{C}\right.$ two-dimensional COSY NMR) spectra were recorded on $300 \mathrm{MHz}$ or $400 \mathrm{MHz}$ spectrometers (Bruker) in $\mathrm{CDCl}_{3}$ and DMSO- $d_{6}$ using TMS as an internal standard. Chemical shifts are reported in parts per million ( $\delta$ ), coupling constants ( $J$ values) are reported in Hertz $(\mathrm{Hz})$ and spin multiplicities are indicated by the following symbols: s (singlet), d (doublet), t (triplet), m (multiplet). ${ }^{13} \mathrm{C}$ NMR spectra were routinely run with broadband decoupling. Pre coated silica gel on aluminium plates (Merck) were used for TLC analysis with a mixture of petroleum ether $\left(60-80^{\circ} \mathrm{C}\right)$ and ethyl acetate as the eluent. Electrospray ionization (ESI) mass spectra were obtained on an LCQ Fleet mass spectrometer, Thermo Fisher Instruments Limited, US and an Agilent mass spectrometer. Infrared spectra were recorded on a Shimadzu FTIR instrument (KBr pellet). Elemental analyses were performed on a Perkin Elmer 2400 Series II Elemental CHNS analyser. The NH signal, being very broad, is not noticed in many ${ }^{1} \mathrm{H}$ NMR spectra.

\section{General procedure}

Synthesis of 3: A mixture of $\alpha$-azidochalcone 1 (1.0 equiv) and carboxylic acid 2 (1.0 equiv or slight excess, if liquid acid was employed) was taken in a $10 \mathrm{~mL}$ quartz vial and placed in the microwave oven. The vial was sealed with a pressure cap and subjected to microwave irradiation. The irradiation was programmed between $100-200{ }^{\circ} \mathrm{C}, 120 \mathrm{~W}, 5 \mathrm{bar}$, for $5 \mathrm{~min}$ depending on the boiling point/melting point of the respective carboxylic acids. The reaction was monitored by TLC using petroleum ether/ethyl acetate mixture (7:3) as the eluent. After the reaction was cooled to room temperature ice-cold water was added. The precipitate obtained was filtered, dried in vacuum and recrystallized from ethanol to afford $\mathbf{3}$.

Representative scale-up example for the synthesis of $3 \mathrm{e}$ using the $80 \mathrm{~mL}$ vessel: In an $80 \mathrm{~mL}$ glass vessel was placed $\alpha$-azidochalcone 1 ( $\mathrm{R}^{1}=4-\mathrm{Cl}, \mathrm{R}^{2}=4$-OMe, $2.0 \mathrm{~g}, 1.0$ equiv), acetic acid $\mathbf{2 b}(0.4 \mathrm{~mL}, 1.0$ equiv slight excess). The vessel was sealed with a pressure cap and placed into the microwave cavity. The irradiation was programmed at $100{ }^{\circ} \mathrm{C}, 120 \mathrm{~W}$, $5 \mathrm{bar}$, for $5 \mathrm{~min}$. After allowing the reaction mixture to cool to room temperature, ice-cold water was added. The precipitate obtained was filtered, dried in vacuum and recrystallized from ethanol to afford $3 \mathbf{e}$ (yield: $1.93 \mathrm{~g}$; 88\%).

Synthesis of 7: To a stirred solution of triphenylphosphine (2.0 equiv) and iodine in dichloromethane, triethylamine was added slowly. After 10 minutes a solution of $\alpha$-amido-1,3-diketone 3 (1.0 equiv) in dichloromethane $(5 \mathrm{~mL})$ was added dropwise. The completion of reaction was monitored by TLC employing petroleum ether/ethyl acetate mixture (8:2) as the eluent. After completion of the reaction, the solvent was removed in vacuo, and the residue was directly purified by column chromatography on silica gel (hexane/ethyl acetate 9:1) to yield oxazole 7 .

Synthesis of 8: In a dry two neck round bottom reaction vessel equipped with a calcium guard tube and a magnetic bar, $\alpha$-azidochalcone (1.0 equiv) was taken and trifluoro acetic acid 
(2.0 equiv) was added to the reaction vessel dropwise at $0{ }^{\circ} \mathrm{C}$. Then, the temperature of the reaction mixture was slowly raised to room temperature in $30 \mathrm{~min}$. The reaction was monitored by TLC using petroleum ether/ethyl acetate mixture $(4: 1)$ as the eluent. After completion of the reaction, the mass was treated with ice cold saturated solution of sodium bicarbonate and extracted with ethyl acetate $(2 \times 10 \mathrm{~mL})$. The combined organic layers were dried with anhydrous $\mathrm{Na}_{2} \mathrm{SO}_{4}$ and concentrated in vacuo to afford oxazole $\mathbf{8}$.

Representative scale-up example for the synthesis of 8a: In a $25 \mathrm{~mL}$ dry two neck round bottom reaction vessel equipped with a calcium guard tube and a magnetic bar, $\alpha$-azidochalcone $1\left(\mathrm{R}^{1}=\mathrm{H}, \mathrm{R}^{2}=\mathrm{H}, 2.0 \mathrm{~g}, 1.0\right.$ equiv) was taken and trifluoroacetic acid (2a, $1.2 \mathrm{~mL}, 2.0$ equiv) was added to the reaction vessel dropwise at $0{ }^{\circ} \mathrm{C}$. The temperature of the reaction mixture was slowly raised to room temperature in $30 \mathrm{~min}$. The reaction was monitored by TLC using petroleum ether/ethyl acetate mixture (8:2) as the eluent. After completion of the reaction, the resultant mass was treated with an ice-cold saturated solution of sodium bicarbonate and extracted with ethyl acetate $(3 \times 10 \mathrm{~mL})$. The combined organic layers were dried over anhydrous $\mathrm{Na}_{2} \mathrm{SO}_{4}$ and concentrated in vacuo to afford oxazole $\mathbf{8 a}$ (yield: $1.52 \mathrm{~g} ; 60 \%$ ).

\section{Supporting Information}

\section{Supporting Information File 1}

Characterization data of new compounds $\mathbf{3}, \mathbf{7}$ and $\mathbf{8}$ and copies of ${ }^{1} \mathrm{H}^{13} \mathrm{C}$, two-dimentional NMR and ESI mass spectra.

[http://www.beilstein-journals.org/bjoc/content/ supplementary/1860-5397-11-219-S1.pdf]

\section{Acknowledgements}

The authors thank DST, New Delhi for assistance under the IRHPA program for the NMR facility. K. R. gratefully acknowledges the award of a Junior Research Fellowship and financial support from CSIR (Grant No. 02 (0061) /12/ EMRII), New Delhi.

\section{References}

1. Shao, J.; Yu, W.; Shao, Z.; Yu, Y. Chem. Commun. 2012, 48, 2785-2787. doi:10.1039/c2cc17850h

2. Xie, H.; Yuan, D.; Ding, M.-W. J. Org. Chem. 2012, 77, 2954-2958. doi:10.1021/jo202588

3. Xie, H.; Liu, J.-C.; Wu, L.; Ding, M.-W. Tetrahedron 2012, 68, 7984-7990. doi:10.1016/j.tet.2012.07.002

4. Suresh, R.; Muthusubramanian, S.; Boominathan, M.; Manickam, G. Tetrahedron Lett. 2013, 54, 2315-2320.

doi:10.1016/j.tetlet.2013.02.033
5. Rajaguru, K.; Suresh, R.; Mariappan, A.; Muthusubramanian, S.; Bhuvanesh, N. Org. Lett. 2014, 16, 744-747. doi:10.1021/ol403456b

6. Liu, S.; Chen, W.; Luo, J.; Yu, Y. Chem. Commun. 2014, 50, 8539-8542. doi:10.1039/c4cc03462g

7. Claiborne, C. F.; Liverton, N. J.; Nguyen, K. T. Tetrahedron Lett. 1998, 39, 8939-8942. doi:10.1016/S0040-4039(98)02058-9

8. Davies, J. R.; Kane, P. D.; Moody, C. J. Tetrahedron 2004, 60, 3967-3977. doi:10.1016/j.tet.2004.03.037

9. Frantz, D. E.; Morency, L.; Soheili, A.; Murry, J. A.; Grabowski, E. J. J.; Tillyer, R. D. Org. Lett. 2004, 6, 843-846. doi:10.1021/ol0498803

10. Fowler, F. W.; Hassner, A. J. Am. Chem. Soc. 1968, 90, 2875-2881. doi:10.1021/ja01013a026

11. Kakehi, A.; Ito, S.; Manabe, T.; Amano, H.; Shimaoka, Y. J. Org. Chem. 1976, 41, 2739-2742. doi:10.1021/jo00878a020

12. Palacios, F.; de Retana, A. M. O.; de Marigorta, E. M.; de los Santos, J. M. Eur. J. Org. Chem. 2001, 2401-2414. doi:10.1002/1099-0690(200107)2001:13<2401::AID-EJOC2401>3.0.C O;2-U

13. Yang, J.-Y.; Lo, Y.-H.; Huang, S.-L.; Lin, Y.-C. Organometallics 2001, 20, 3621-3623. doi:10.1021/om010377t

14. Ooi, T.; Takahashi, M.; Doda, K.; Maruoka, K. J. Am. Chem. Soc. 2002, 124, 7640-7641. doi:10.1021/ja0118791

15. Prechter, A.; Henrion, G.; Faudot dit Bel, P.; Gagosz, F. Angew. Chem., Int. Ed. 2014, 53, 4959-4963. doi:10.1002/anie.201402470

16. Padwa, A.; Crosby, K. J. Org. Chem. 1974, 39, 2651-2653. doi:10.1021/jo00931a054

17. Alper, H.; Prickett, J. E.; Wollowitz, S. J. Am. Chem. Soc. 1977, 99 , 4330-4333. doi:10.1021/ja00455a020

18. Pinho e Melo, T. M. V. D.; Cardoso, A. L.; Gomes, C. S. B.; d'A Rocha Gonsalves, A. M. Tetrahedron Lett. 2003, 44, 6313-6315. doi:10.1016/S0040-4039(03)01534-X

19. Candito, D. A.; Lautens, M. Org. Lett. 2010, 12, 3312-3315. doi:10.1021/ol100975b

20. Jana, S.; Clements, M. D.; Sharp, B. K.; Zheng, N. Org. Lett. 2010, 12, 3736-3739. doi:10.1021/ol101130e

21. Khlebnikov, A. F.; Golovkina, M. V.; Novikov, M. S.; Yufit, D. S. Org. Lett. 2012, 14, 3768-3771. doi:10.1021/ol3016594

22. Khlebnikov, A. F.; Novikov, M. S. Tetrahedron 2013, 69, 3363-3401. doi:10.1016/j.tet.2013.02.020

23. Sjöholm Timén, A.; Somfai, P. J. Org. Chem. 2003, 68, 9958-9963. doi:10.1021/jo0352326

24. Li, X.; Du, Y.; Liang, Z.; Li, X.; Pan, Y.; Zhao, K. Org. Lett. 2009, 11, 2643-2646. doi:10.1021/ol9006663

25. Okamoto, K.; Mashida, A.; Watanabe, M.; Ohe, K. Chem. Commun. 2012, 48, 3554-3556. doi:10.1039/c2cc30745f

26. Alvernhe, G.; Laurent, A.; Masroua, A. Tetrahedron Lett. 1983, 24 , 1153-1156. doi:10.1016/S0040-4039(00)86390-X

27. Pinjo e Melo, T. M. V. D.; Lopes, C. S. J.; d'a Rocha Gonsalves, A. M.; Beja, A. M.; Paixão, J. A.; Silva, M. R.; da Veiga, L. A. J. Org. Chem. 2002, 67, 66-71. doi:10.1021/jo010504v

28. Palacios, F.; Aparicio, D.; de Retana, A. M. O.; de los Santos, J. M.; Gil, J. I.; Alonso, J. M. J. Org. Chem. 2002, 67, 7283-7288. doi:10.1021/jo025995d

29. Nair, V.; George, T. G. Tetrahedron Lett. 2000, 41, 3199-3201. doi:10.1016/S0040-4039(00)00350-6

30. Perreux, L.; Loupy, A. Tetrahedron 2001, 57, 9199-9223. doi:10.1016/S0040-4020(01)00905-X

31. Diaz-Ortiz, A.; de la Hoz, A.; Langa, F. Green Chem. 2000, 2, 165-172. doi:10.1039/B003752O 
32. Tanaka, K.; Toda, F. Chem. Rev. 2000, 100, 1025-1074. doi:10.1021/cr940089p

33. Singh, P. N. D.; Carter, C. L.; Gudmundsdóttir, A. D. Tetrahedron Lett. 2003, 44, 6763-6765. doi:10.1016/S0040-4039(03)01558-2

34. Wipf, P.; Miller, C. P. J. Org. Chem. 1993, 58, 3604-3606. doi:10.1021/jo00066a004

35. Sanz-Cervera, J. F.; Blasco, R.; Piera, J.; Cynamon, M.; Ibáñez, I.; Murguía, M.; Fustero, S. J. Org. Chem. 2009, 74, 8988-8996. doi:10.1021/jo9016265

36. Takeuchi, H.; Kitamura, Y.; Hayakawa, S.; Koyama, K. J. Chem. Soc., Chem. Commun. 1989, 1414-1415. doi:10.1039/C39890001414

\section{License and Terms}

This is an Open Access article under the terms of the Creative Commons Attribution License

(http://creativecommons.org/licenses/by/2.0), which permits unrestricted use, distribution, and reproduction in any medium, provided the original work is properly cited.

The license is subject to the Beilstein Journal of Organic Chemistry terms and conditions:

(http://www.beilstein-journals.org/bjoc)

The definitive version of this article is the electronic one which can be found at: doi:10.3762/bjoc.11.219 